\title{
Wireless Self Control System for Domestic Appliances
}

\section{Akshay Patil, Tirupati Pallewad, Bajrang Thakur and Sayali N. Mane}

\begin{abstract}
Nowadays there is a tremendous growth in the wireless Technology. Internet of things or IoT is the best promising wireless technology used for connecting, controlling the devices connected to the Internet through IP address. With this technology, it is possible to provide flexible and low-cost home automation system. In the present times most of the people are clinging to their mobile phones throughout the day. So using the mobile app we can connect, control domestic appliances. This paper presents an overalldescription of IoT-based applications like smart cities, smart homes
\end{abstract}

Keywords

Domestic appliances control,

Internet of things(IoT),

The Internet through IP address,

Low-cost home automation,

Wireless technology

\section{INTRODUCTION}

The concepts of home automation become practical since the 20th century [1]. It is because of introduction of electricity and rapid growth in information technology [2]. Smart home system is nothing but the technology used in home environment to provide comfort, security and minimum efforts by using Internet of things [3]. IoT is nothing but the physical objects communicating to each other, machine to machine, person to machine communication [4]. While developing smart City, smart home plays very important role.

Government of India and other country has proposed to develop smart cities across country, which will demand smart home automation [5].

IoT technology included right from the planning stage will mainly help in reducing the utilization of electricity, save water and other limited resources but increases the comfort for humans [6]. Home automation integrate various sub-systems which are required a level of standardization to assurance interoperability. The smart device take decisions in a cooperative as well as disseminated way and to trigger action or actuate, is essential to make sure that decisions that are taken for actions [7]. Some of the application module in smart homes where the concept of IoT is being used is in controlling air conditioner based on temperature, humidity, and moisture in the surrounding environment [8]. Other smart devices act as a controlling devices in the home and providing energy savings, and comfort, also interconnected other services by cloud for efficient and comfortable [9]. These smart devices allow the users to controlling the light's intensity in the home to the desired brightness level [10]. Smart lighting solutions such as hue smart lights designed and developed by different companies [11] can be used to provide mood based lighting, send alert signals etc. Controlling the entertainment system using voice commands, gestures etc are common application in modern cities [12]. The current generation of smart televisions from various manufacturers has these features inbuilt in them. Automated controlling of blinds to draw themselves close or open based on the intensity of sunlight or time of the day [13]. Controlling devices based on audio or voice commands. Amazon Echo by Amazon and Google home from Google are two of the many voice assistant devices that are capable of listening to voice commands and respond accordingly or provide weather updates, real-time traffic updates, set alarms and many such actions [14]. In this paper we are going to discuss about controlling of domestic appliances from indoor and outdoor environment.

\section{OVERVIEW OF THE DESIGN METHODOLOGY}

When people think about home automation, most of them may imagine living in Smart home. To some extent home automation equals to smart home. The basic idea of home automation is to control domestic appliances [15]. Home Automation is useful for elderly and disabled people to increase quality of life [16].

In recent years the growth of home automation increases because of its simplicity through mobile connectivity. We can achieve this home automation 
by different technique that is by Bluetooth, Wi-Fi based, IoT [17].

The most reliable and flexible technique is IoT, so the person can control the domestic appliances from any corner of the world.

The concept of Smart home is new in India so here we are trying to develop a system so that middle class as well as low class family can afford it. So digitalization will get successful in India.

To develop a Smart Home Control and Monitoring System by harnessing the power of IoTs at low-cost this provides flexible and scalable architecture for home automation. It will provides security, energy efficiency and ease of use with capability of controlling and monitoring home appliances from anywhere in the world.

The general flowchart of the process of design any controlling methodology of home appliances is given below in Fig 1.

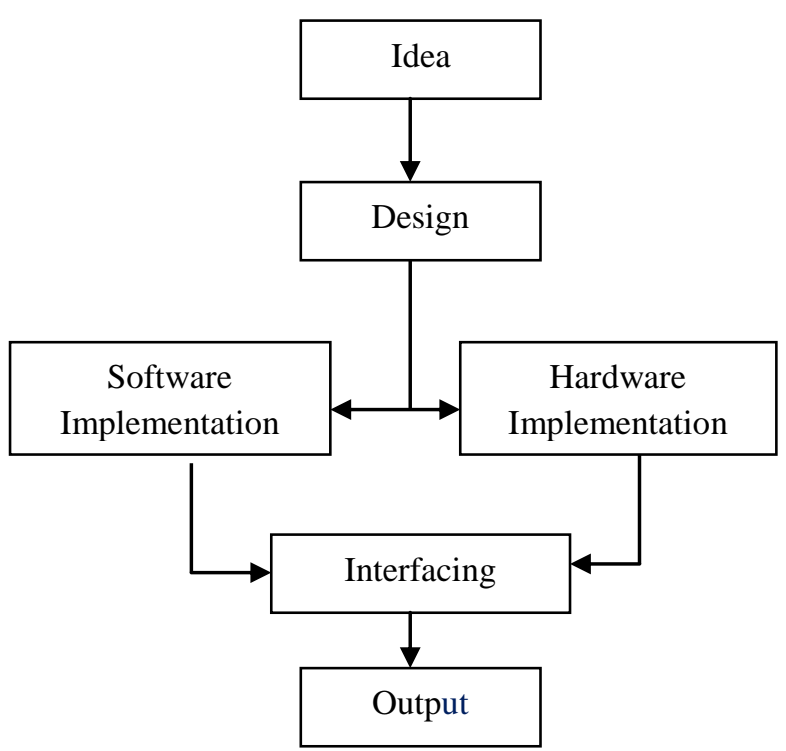

Fig 1. Design overview of the process.

\section{ARDUINO UNO BASED IMPLEMENTATION}

The IoT based implementations generally classify into two categories, indoor environment and outdoor environment which are discussed briefly.

\section{A. Indoor Environment}

In this paper, concept of Home Automation using IoT is realised by using low cost microcontroller based Arduino Uno board and android phone. Arduino is a open source platform so that anyone can control it by programming it. Here we are connecting $\mathrm{Wi}-\mathrm{Fi}$ module ESP8266 to Arduino board. Programming for interfacing of ESP8266 to Arduino should be done properly. So that depending on the received signal board gives proper output.

Since, the mobile phone is a wireless communication device, so connection between Arduino and mobile is done by using Wi-Fi module. Android app is developed by using platform of Android studio. This Android application contains the switches like fan, light etc. Any change of the status by clicking on button on android app.

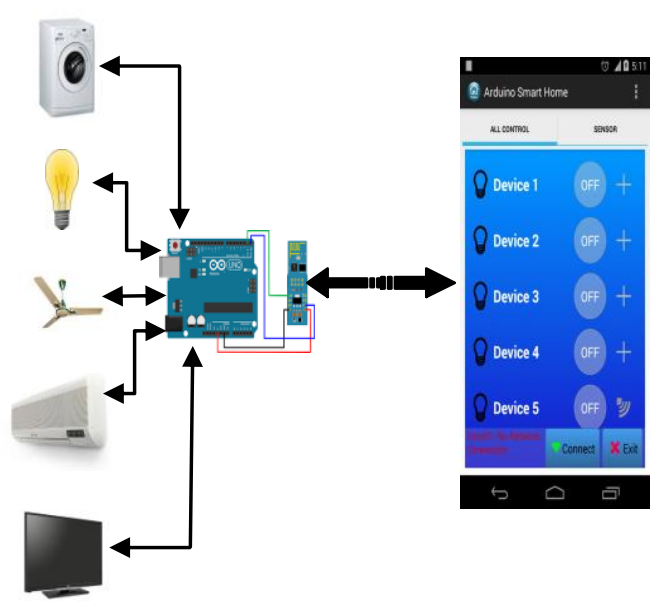

Fig 2. Handling of domestic appliances with indoor environment.

\section{B. Outdoor Environment}

The control of domestic appliances from outside of home is complex task. Arduino's Wi-Fi module IP address and port number can be used to locate remote devices connected to Internet in a smart home environment.

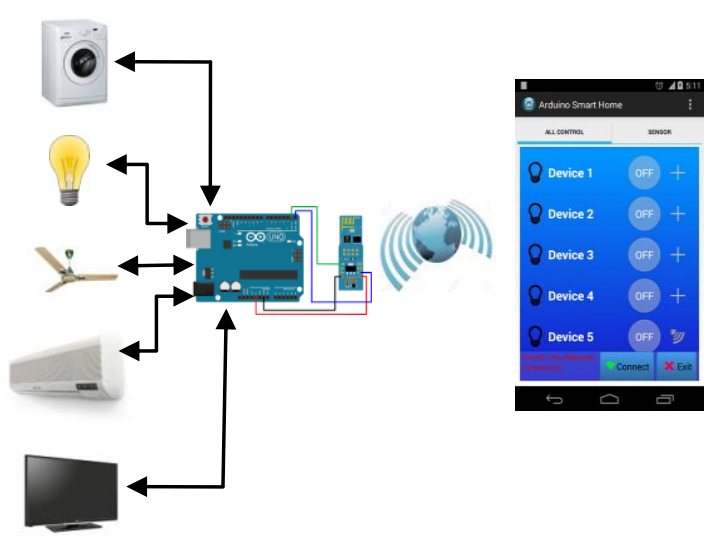


Fig 3. Handling of the domestic appliances with outdoor environment.

Here cloud is used to store the status report of the device. Thus here we can control the devices through the use of Internet facility.

\section{Typical Applications}

The proposed system has the capabilities to control the following appliances:

1. Temperature and Humidity.

2. Motion detection.

3. Fire and smoke detection.

4. Light dimmer.

5. Lights on/off.

6. Fan on/off etc.

\section{CONCLUSION}

Wi-Fi technology is capable to provide a smart solution to control remotely different home applicants and also provide better home security in comparison with existing system. IoT enable system also chipper in comparison with available solution. The system design and architecture were discussed, and presents the basic level of home appliance control and remote monitoring can be implemented. Finally the IoT enable system is better from the scalability and flexibility point of view than the commercially available home automation system. Hence we can conclude that the required goals and objectives of home automation system can be achieved easily.

\section{REFERENCES}

[1] Chen, S. Y., \& Chang, S. F. (2009). A review of Smart Living space development in a cloud computing network environment. Computer-Aided Design and Applications, 6(4), 513-527.

[2] McFarland, James Robert, John Matthew Reilly, and Howard J. Herzog. "Representing energy technologies in top-down economic models using bottom-up information." Energy Economics 26.4 (2004): 685-707.

[3] Tsai, C. W., Lai, C. F., Chiang, M. C., \& Yang, L. T. (2014). Data mining for Internet of Things: A survey. IEEE Communications Surveys and Tutorials, 16(1), 77-97.

[4] Atzori, L., Iera, A., \& Morabito, G. (2010). The internet of things: A survey. Computer networks, 54(15), 2787-2805.

[5] Lin, C. C., Yang, C. H., \& Shyua, J. Z. (2013). A comparison of innovation policy in the smart grid industry across the pacific: China and the USA. Energy Policy, 57, 119-132.

[6] Dincer, I., \& Rosen, M. A. (1999). Energy, environment and sustainable development. Applied energy, 64(1), 427-440.

[7] Omer, A. M. (2008). Green energies and the environment. Renewable and Sustainable Energy Reviews, 12(7), 1789-1821.

[8] Murakami, S., Kato, S., \& Zeng, J. (2000). Combined simulation of airflow, radiation and moisture transport for heat release from a human body. Building and environment, 35(6), 489-500.

[9] Lee, E., Lee, E. K., Gerla, M., \& Oh, S. Y. (2014). Vehicular cloud networking: architecture and design principles. IEEE Communications Magazine, 52(2), 148-155.

[10] Ko, P. R. T., Kientz, J. A., Choe, E. K., Kay, M., Landis, C. A., \& Watson, N. F. (2015). Consumer sleep technologies: a review of the landscape. Journal of clinical sleep medicine: JCSM: official publication of the American Academy of Sleep Medicine, 11(12), 1455.

[11] O'Brien, W., Kapsis, K., \& Athienitis, A. K. (2013). Manually-operated window shade patterns in office buildings: A critical review. Building and Environment, 60, 319-338.

[12] Chardon, J. M., Patel, S., Kirkley, P., Gujral, R., Persaud, L., Simon, K., \& Raeber, E. (2011). U.S. Patent Application No. 13/332,907.

[13] Reinhart, C. F., Mardaljevic, J., \& Rogers, Z. (2006). Dynamic daylight performance metrics for sustainable building design. Leukos, 3(1), 7-31.

[14] Perera, C., Liu, C. H., Jayawardena, S., \& Chen, M. (2014). A survey on internet of things from industrial market perspective. IEEE Access, 2, 1660-1679.

[15] Srivastava, R., Kumar, N., Barnwal, A., \& Singh, S. (2017). Grid Interactive Solar Powered Automated Bottling Plant Using Microcontroller. International Journal of Advanced Engineering and Management, 2(1), 9-14.

[16] Kumar, M., Kabir, F., \& Roy, S. (2017). Low Cost Smart Stick for Blind and Partially Sighted People. International Journal of Advanced Engineering and Management, 2(3), 65-68.

[17] Want, Roy, Bill N. Schilit, and Scott Jenson. "Enabling the internet of things." Computer 48, no. 1 (2015): 28-35. 
email: Patil.akshay060@gmail.com

Tirupati Pallewad

Department of Electronics and Telecommunication Engineering, D.Y.Patil college of Engineering,

Akurdi, Pune, India

email: pallewadtirupati@gmail.com

Bajrang Kacchave

Department of Electronics and Telecommunication Engineering, D.Y.Patil college of Engineering,

Akurdi, Pune, India

email: kacchavebajrang@gmail.com

Sayali N. Mane

Department of Electronics and Telecommunication Engineering, D.Y.Patil college of Engineering,

Akurdi, Pune, India

Aemail: sayalimane@ rediffmail.com

\author{
Akshay Patil \\ Department of Electronics and Telecommunication \\ Engineering, D.Y.Patil college of Engineering, \\ Akurdi, Pune, India
}

